\title{
BESLENME ALZHEIMERDAN KORUYUCU BİR FAKTÖR MÜDÜR?
}

\author{
Gökcen IPLIKÇCi \\ Nurcan YABANCI AYHAN ${ }^{2}$
}

\section{ÖZET}

Tüm dünyadaki 35 milyon demans hastasının yaklaşık \%75'inin alzheimer hastası olduğu düşünülmektedir. Türkiye'de ise 250-300 bin alzheimer hastası bulunmaktadır ve bu sayının her 20 yılda ikiye katlanacağı tahmin edilmektedir.

Yaşam süresinin uzatılması ve kalitesinin artııılması için yeterli ve dengeli beslenme çok önemlidir. Son dönemde alzheimerın prevalansı ve insidansının artmasında beslenmenin etkili olduğunu gösteren çalışmalar bulunmaktadır. Bu konuda özellikle oksidatif stresin azalmasına yardımcı olan A, C, E vitamini gibi antioksidan ögeler ve hiperhomosisteinemiyi önleyen B grubu vitaminleri üzerinde durulmaktadır. Yapılan bazı çalışmalarda ise omega-3 yağ asidi alımının arttıııması ve total/doymuş yağ asidi alımının azaltılması da alzheimer ile ilişkili bulunmuştur.

Sonuç olarak yaşam boyu meyve, sebze ve deniz ürünlerinden zengin beslenmenin alzheimerdan koruyucu olduğu tahmin edilmektedir. Bu alanda daha fazla kontrollü bilimsel araştırma yapılmasına ihtiyaç vardır.

Anahtar Kelimeler: Alzheimer, Beslenme, Yaşılık

\section{Is Nutrition A Protector Factor From Alzheimer?}

\section{Abstract}

Approximately $75 \%$ of 35 million dementia patients worldwide are thought to have Alzheimer's disease. In Turkey, there are 250-300 thousand Alzheimer's patients and it is estimated that this number will double in 20 years.

1 Arş. Gör., Ankara Üniversitesi Sağlık Bilimleri Fakültesi Beslenme ve Diyetetik Bölümü, Ankara, gokcen_iplikci@hotmail.com

2 Prof. Dr., Ankara Üniversitesi Sağlık Bilimleri Fakültesi Beslenme ve Diyetetik Bölümü, Ankara,nyabanci@gmail.com 
Sufficient and balanced nutrition is crucial for the prolongation of life and the increase in life quality. Recent studies have shown that nutrition is effective in increasing the prevalence and incidence of Alzheimer's. In this regard, we focus particularly on antioxidant substances such as vitamins $A$, $\mathrm{C}$ and $\mathrm{E}$, which help to reduce oxidative stress, and vitamins of group $\mathrm{B}$, which inhibit hyperhomocysteinemia. In some studies, increasing omega-3 fatty acid intake and decreasing total/saturated fat acid intake have also been associated with Alzheimer's.

As a result, throughout life fruit, vegetable and seafood rich nutrition is estimated to protect against alzheimer. More controlled scientific research is needed in this area.

Keywords: Alzheimer, Nutrition, Aging

\section{GíRiş VE AMAÇ}

Ülkemizde ve dünyada yaşı nüfusun artması, yaşlılarda görülen sağlık sorunlarının görülme sıklığını yükseltmiştir. ${ }^{1}$

Alzheimer hastalığı ilk olarak 1906 yılında Alman nöropatolog Alois Alzheimer tarafından tanımlanmış olup nöral yapılarda hücre kaybıyla karakterize, ilerleyici bir hafıza kaybı tablosudur. ${ }^{2}$ Alzheimer hastalığı tüm diğer demans olgularının \%50-80'ini oluşturmaktadır. ${ }^{3}$ Yaşam kalitesini azaltan alzheimer hastalığının oluşumunda beslenme alışkanlıklarının etkili olduğu düşünülmektedir.

\section{$\mathrm{Bu}$ derleme çalışmada amaç, alzheimer hastalığından korunmada beslenmenin öneminin incelenmesidir.}

\section{Alzheimer Epidemiyolojisi}

Alzheimer hastalığı tüm demans hastalıkları içinde en yaygın görülenidir. Dünya çapında var olan 35 milyon demans hastasının yaklaşık \%75'ini alzheimer tipi demans oluşturmaktadır ve bu prevelansın her 20 yılda ikiye katlanacağı tahmin edilmektedir. Bu sebeple 2050 yılına kadar dünya çapında 115 milyon insanın, sadece hastada değil aynı zamanda hastanın çevresindeki bireyler üzerinde de büyük bir etkiye sahip olan, alzheimer hastalığından muzdarip olacağı tahmin edilmektedir. ${ }^{4}$

Lobo ve arkadaşlarının 2000 yılında Avrupa'da, 10 sene boyunca toplamda 2346 demans hastasını inceleyerek yaptığı çalışmada alzheimer hastalığı sıklığını \%4,4 olarak bulmuşlardır. Amerika'da 
yürütülenbir başka çalışmada ise 71 yaş üzerinde alzheimer prevalansının $\% 9,7$ olduğu gösterilmiştir. ${ }^{5}$

Hastalığın insidansıyla ilgili yapılan çalışmalara bakılacak olursa 65 yaş üzeri bireyler üzerinde yapılan 2 çalışmada; her yıl 1000 kişiden 15'inin bu hastalığa yakalandığı söylenebilir ve bu oran kadınlar ve erkekler için sırasıyla 13,0 ve 16,9 olarak bulunmuştur. ${ }^{6,7}$

İstanbul'un Kadıköy ilçesinde gerçekleştirilen Türkiye Alzheimer Hastalığı Prevalansı Çalışması'nda 70 yaş üzerindekiler arasında alzheimer hastalığı prevalansının \%11 olduğu saptanmıştır. Bu prevalans değerine göre Türkiye'de 250-300 bin alzheimer hastası olduğu söylenebilir. ${ }^{8}$

\section{Alzheimerın Mekanizması}

Alzheimer hastalığının makroskobik patolojik bulgularının beyinde atrofi, giruslarda daralma, sulkuslarda ve ventriküllerde genişleme olduğu bildirilmiştir. Nöron içerisinde birikim gösteren nörofibril yumaklar (NFY), ekstraselüler birikim gösteren amiloid plaklar ve nöron kayıpları da hastalığın temel mikroskobik değişiklikleri olarak kabul edilmektedir. ${ }^{9}$

Alzheimer hastalığında beyinde $\mathrm{Ca}^{+2}$ konsantrasyonu artışının bu iyonla aktive edilen nötralproteinazların aktivasyonunu artırdığı, amiloid plak ve NFY oluşumuna neden olduğu rapor edilmiştir. ${ }^{10}$ Alzheimer hastalığının etiyopatogenezi ile ilişkili hipotezlerden biri de oksidatif stres hipotezidir. Alzheimer hastalığında oksidatif hasarın arttığı ve bu artışın hastalıkta ortayaçıkan nöronal dejenerasyona neden olabileceği ileri sürülmüştür. Alzheimer hastalığının etiyopatogenezindeoksidatif stresin katkısını gösteren bulgular arasında alzheimer hastalarının beyinlerinde serbest radikal oluşumunu uyaran lipidperoksidasyonunun, protein ve DNA oksidasyonunun artmasının yer aldığı bildirilmiştir. ${ }^{11}$

Alzheimer hastalığı için en önemli ve değiştirilmesi mümkün olmayan risk faktörü yaştır. Altmış beş yaşın üzerinde her beş yılda bir prevalans iki katına çıkmaktadır. ${ }^{8,12}$ Bunun yanında down sendromu, düşük eğitim seviyesi, sık kafa travması öyküsü, cinsiyet (kadın olmak) alzheimerın risk faktörleri arasındadır. ${ }^{13}$ Genetik geçişli alzheimer hastalığı ise tüm olguların sadece $\% 5$ kadarını oluşturmaktadır. ${ }^{14}$ 


\section{Alzheimer Hastalığında Klinik Belirtiler ve Evreler}

Başlangıçta sinsi ve progresif bir ilerleme ve bu durumu takip eden hastalıkta tipik olarak bellek defektlerini lisan bozuklukları izler. İleri evrelere kadar yürüme bozuklukları gözlenmez. ${ }^{15}$ Hasta yakınlarının hastalar adına belirttiği ilk yakınma genellikle unutkanlık, yolunu kaybetme, hesaplama yapamamadır. ${ }^{16}$ Hasta yakınları hastanın güvenliği tehlikeye girene kadar hastanın eksikliklerini gidermeye çalışırlar. ${ }^{17}$ Yakın bellek bozuklukları tabloya hâkimdir, uzak bellek çoğunlukla geç dönemlere kadar korunmuş olur. Alzheimer hastalığında nöropsikiyatrik semptomlar depresyon, delüzyon ve halüsinasyonlar (sıklıkla görsel), kişilik değişiklikleri ve davranış bozuklukları olarak sınıflandırılırlar. Alzheimer hastalarında depresyon \%25-30, delüzyon ve halüsinasyon \%20-30 oranında görülmektedir. Davranış bozukluğu olarak sözel ve fiziki agresyon, meraklılık, ajitasyon, uygunsuz cinsel davranış, idrar inkontinansı, tırnak yeme ve kendine zarar verme görülebilmektedir. ${ }^{15}$

Alzheimer hastalığına ait belirtilerin klinik seyrine ilişkin 7 evre tanımlanmıştır:

Birinci evrede birey bilişsel zayıflık semptomları göstermeye başlamıştır.Hastalar cüzdan, anahtar gibi genel objelerin yerlerini unutmaya başladıklarında ikinci evreye girmişlerdir. Evre üçte hastalar konuşma esnasında kelime bulmakta zorlanmaya başlar. Dördüncü evrede bireyin kısa dönem belleğinde önemli kayıplar gözlenmektedir. Hastalar sosyal hayatlarında içlerine kapanık olmaya başlarlar. Evre beşte hastalar zihinsel karışıklık yaşamaya başlar, agnozi (nesneleri tanımada zorluk) ve apraksi (motor beceri hareketlerinde bozulma) gelişir. $\mathrm{Bu}$ dönemden itibaren günlük aktiviteler için yardıma intiyaçları vardır. Afazi (kelime bulma ve konuşmada zorluk) gelişmeye başladığında hastalar altıncı evrededir. Yedinci evre itibariyle hastalar yutma zorlukları dahi yaşayabilirler. ${ }^{18}$

Günümüzde alzheimer hastalığı için \%100'e yakın doğrulukta tanı koymayı mümkün kılan DSM-V (Diagnosticand Statistical Manual of Mental Disorders-5/Tanı Ölçütleri Başvuru El Kitabı) ve NINCDSADRDA (National Institue of Neurological and Communicative Disorders and Stroke-Alzheimer's Disease and Related Disorders Association/Nörolojik, İletişimsel ve Alzheimer Hastalığı Ve İlişkili Hastalıklar Ulusal Enstitüsü) tanı kriterleri kullanılmaktadır.,19 


\section{Alzheımer Hastalığı ve Beslenme}

Sağlığın korunması, sürdürülmesi, hastalıklardan korunma, hastalık oluşumudan sonra tedavi etkinliğinin arttırılması ve tedavi süresinin kısaltılmasında yeterli ve dengeli beslenmek temel bir olgudur. ${ }^{20}$

Son yıllarda birtakım gözlemlere dayanılarak alzheimer hastalığının oluşmasına bazı besin ve besin ögelerinin etkileri olduğu düşünülmektedir. ${ }^{21}$ Beyinde ekstrasellüler amiloid- $\beta$ peptidlerinin birikimi, nöral yıkıma sebep olarak oksidatif stresi arttıran reaktif oksijen türlerinin üretiminin artışıyla ilişkili olduğu bulunmuştur. ${ }^{22}$ Oksidatif stres bir takım diyet bileşenlerinden etkilenmektedir; bu da bazı beslenme alışkanlıklarının alzheimer hastalığında rol oynayabileceği hipotezini desteklemektedir. Özellikle C vitamini, E vitamini, karotenoid gibi antioksidanlardan zengin bazı diyet bileşenlerinin bu hipotezleri desteklediği düşünülmektedir. ${ }^{23}$

Diyet ve alzheimer hastalığı arasındaki bir diğer hipotez ise homosistein seviyelerinin artışı ile ilgilidir. İn vitro olarak homosisteininamoloid- $\beta$ prokürsörilerinin birikimini arttırdığı, bu yüzden de vasküler mekanizmalarla ya da nörotoksin olarak alzheimer oluşumuna yol açtığı düşünülmektedir. ${ }^{24}$ Homosisteininmetabolik yolundaki kofaktörlerden olan $B_{6}, B_{12}$ ve folik asit gibi $B$ grubu vitaminlerinin nörodejenaratif hastalıklarla ilişkili olduğu gösterilmiştir. ${ }^{25}$

E vitamini beyindeki majör lipofilik antioksidandır. Kolay oksitlenebilen çeşitli bileşiklerin oksitlenmesini önleyerek bu işlevini yerine getirir. Vücut dokularında doymamış yağ asitlerinin oksidasyonunu ve özellikle mide ile karaciğerde $A$ vitamininin oksidasyonunu önler. ${ }^{26}$ Beyindeki lipidleri oksidatif strese karşı korur ve alzheimer hastalarında beyin omurilik sıvısında $E$ vitamini seviyesi düşük bulunmuştur. ${ }^{27}$ Bunun yanında organizmanın çalışmasında birçok fonksiyonu bulunan $\mathrm{C}$ vitamini $\mathrm{E}$ vitamininin organizmada daha elverişli olarak kullanılmasında etkilidir ${ }^{26}$ Engelhart ve ark. ${ }^{28}$ yaptıkları yaklaşık 6 yıl takipli bir çalışmada $\beta$-karoten, $C$ vitamini ve $E$ vitamininin demans hastalıkları üzerine ilişkisini incelemişlerdir. 5395 bireyin katılımıyla gerçekleştirilen çalışmada DSM-III kriterleri alzheimer hastalığı teşhisi için kullanılmıştır. 6 yılın sonunda 146 bireyde alzheimer hastalığı gelişmiştir. Besin tüketim sıklığı anketlerinin verilerine göre yüksek düzeyde $C$ vitamini ve $E$ vitamini alımının alzheimer hastalığı olma riskini azalttığını bulmuşlardır. ${ }^{28}$ 
İngiltere'de yapılan plasebo-kontrollü bir çalışmada 2 yıl süresince alzheimer hastalarına günde $2000 \mathrm{IU}$ a-tokoferol verilmiştir. Plasebo ve kontrol gruplarının başlangıç ve bitiş anındaki mini mental test skorları, günlük aktiviteleri kıyaslandığında a-tokoferol kullanan grubun daha az kayba uğradığı ve günlük aktivitelerini daha iyi yerine getirebildiği görülmüştür. ${ }^{29} \mathrm{E}$ ve $\mathrm{C}$ vitamini suplemanlarının alzheimer hastalığı prevelans ve insidansına etkisi üzerine yapılan bir çalışmada da bu iki vitamin kombinasyonunun supleman halinde alınmasının hem prevelansı hem insidansı azalttığını bulunmuştur. ${ }^{30}$ Folik asit, $B_{6}$ ve $B_{12}$ vitaminleri, homosisteininmetionine dönüşmesinde ve $S$ AdenozilMetiyonin (SAM) sentezinde kofaktör olarak çalışmaktadır. Metiyonin, metiyoninadenozintransferaz (MAT) enzimi aracılığıyla ATP ile birleşir ve SAM ortaya çıkar. SAM ise nöral membranlardaki fosfolipidlerin metilasyonunda görev almaktadır. Metiyonin metabolizmasının toksik bir ürünü olarak ortaya çıkan ve sülfidril grubu içerien bir amino asit olan homosistein, metilasyon reaksiyonlarına engel olmaktadır. McMahon ve ark. ${ }^{31}$ Yeni Zelanda'da yapmış olduğu plasebo-kontrol çalışmasında;65 yaş üzeri bireylere iki sene boyunca folik asit, $B_{6}$ ve $B_{12}$ vitaminleri verilmiştir. Günlük yaşam aktivite hızlarına bakıldığında plasebo grubunda giderek azalma olduğu saptanmıştır. ${ }^{31}$ Sadece folik asit suplementasyonunun kullanıldığı bir başka çalışmada ise her gün folik asit suplementasyonu alan alzheimer hastası grubun almayanlara göre mini mental test skorlarındaki düşüşün daha yavaş olduğu gözlenmiştir. ${ }^{32}$

Santral sinir sistemi sağlığının sürdürülmesinde önemli rol oynayan antioksidan vitaminlerden biri de $A$ vitaminidir. Alzheimer hastalığına sahip bireylerde $A$ vitamini ve $\beta$-karotenin serum ve plazma konsantrasyonu düşük bulunmuştur. ${ }^{33}$ Isviçre'de yaşları 65 ile 94 arasında değişen 442 alzheimer hastasının katıımıyla yapılan bir çalışmada $\beta$-karotenin plazma konsantrasyon yüksekliğinin artmasıyla hafıza performansının iyileştiği bulunmuştur ${ }^{34}$

Santral sinir sisteminde nörotransmitter seviyeleri ile ilişkili olduğu düşünülen $D$ vitamininin iki formu bulunmaktadır. Biyolojik olarak daha aktif olan $D_{3}$ vitamini (kolekalsiferol) daha çok insan vücudunda sentezlenen formu iken, $D_{2}$ vitamini (ergokalsiferol) özellikle diyetle alınan formudur. ${ }^{35}$ Annweiler ve ark. ${ }^{36}$ plazma $D$ vitamini seviyeleri düşük, 120 alzheimer hastasına 24 hafta boyunca oral $D_{3}$ vitamini suplemantasyonu vererek yaptıkları çalışmada, $D_{3}$ vitamininin artışını bilişsel performans gelişimi ile ilişkili bulmuşlardır. ${ }^{36} D_{3}$ vitamininin 
aksine $D_{2}$ için yapılan bir çalışmada sonuçlar bu yönde bulunmamıştır. ${ }^{37}$

Günlük beslenmede hidrojene edilmiş yağ ile doymuş yağ tüketiminin düşük düzeyde, bitkisel kaynaklardan alınan çoklu doymamış yağ asitlerinin ve balıktan alınan omega-3 çoklu doymamış yağ asitlerinin yüksek düzeyde tutulmasının demans riskini azalttığı bildirilmiştir. ${ }^{38}$ Besin tüketim anketlerinin yardımıyla 1993-2000 yılları arasında 65-94 yaşları arasında toplamda 815 bireyin katılımıyla yapılan araştırmada bu bireylerden 131 'inde alzheimer hastalığı geliştiği tespit edilmiştir. Bu araştırmadahaftada bir ve daha fazla balık tüketenlerde $\% 60$ daha az alzheimer riski olduğu ortaya konmuştur. Çalışmada EPA alzheimer hastalığı ile ilişkilendirilemezken; DHA ve total omega-3 alımının artması ile alzheimer hastalığına yakalanma riskinin azaldığı vurgulanmıştır. ${ }^{39}$ Madrid'de yapılan bir başka çalışmada ise yedi gün art arda besin tüketim kaydı alınarak beslenmeleri değerlendirilen hastalardan tekli doymamış yağ asitleri, doymuş yağ asitleri ve kolesterol tüketimi düşük olanların yüksek olanlara göre mini mental test skorları anlamlı derecede daha yüksek bulunmuştur. $\mathrm{Bu}$ hastaların meyve, karbonhidrat, tiamin, folat ve C vitamini alımlarına bakıldığında ise bunların yüksek alımında mini mental test skorlarının yükseldiği saptanmıştır. ${ }^{40}$

Reaktif oksijen türlerinin yarattığı tehlikeye karşı bir savunma sistemi olarak çalışan antioksidatif enzim sistemleri (süper oksit dismutaz, glutatyonperoksidaz gibi) için katalaz olarak görev yapan selenyum, bakır ve çinko minerallerinin de alzheimer hastalığından korunmada ve hastalığın tedavisinde etkili olabileceği düşünülmektedir. ${ }^{41}$ Vural ve ark. ${ }^{41}$ yaptığı bir kontrol çalışmasında da alzheimer hastalarının sağlıklı bireylere göre plazma selenyum, bakır ve çinko seviyeleri düşük çıkmıştır. ${ }^{41}$ Bir başka çalışmada ise 24 alzheimer hastası bireyin plazma çinko seviyeleri ile bilişsel fonksiyonları arasında pozitif yönde korelasyon bulunmuştur. ${ }^{42}$ Türkiye'de yapılan bir çalışmada ise serum çinko düzeyindeki artışın alzheimer riskini azalttığı saptanırken, serum bakır düzeyindeki artışın alzheimer riskini arttırdığı ortaya konmuştur. ${ }^{43}$

\section{Sonuç ve Öneriler}

Günümüzde tıp dünyasındaki gelişmeler ile yaşam süresi artmaktadır. Bunun bir getirisi olarak demans gibi geriatrik 
hastalıklarda daha fazla karşımıza çıkmaktadır. Yaşam süresinin yanı sıra yaşam kalitesini de korumak ve arttırmak için sağlıklı beslenmeyi bir yaşam şeklihaline getirmek oldukça önemlidir. Alzheimer ve diğer nörolojik hastalıklarından korunmada da homosistein metabolizmasında görevleri olan ya da antioksidan olarak işlev gören vitamin ve mineralleri önerilen alım düzeylerinde hayat boyu almanın önemi göz ardı edilmemelidir.

\section{KAYNAKLAR}

1. Özenoğlu A, Sökülmez P. Hastalıklarda beslenme tedavisi. 1. Baskı. Ankara: HatiboğluYayınları 2013; 757-805,

2. Michel G, Bernardino G. Alois Alzheimer: His life and times. Brain Pathology 2007; 17:57-62.

3. Perkins P, Annegers JF, Doody RS. Incidence and prevalance of dementia in a multiethnic cohort of municipal retirees. Neurology 1997; 49:44-50

4. Povova J, Ambroz P, Bar M, Pavukova V, Sery O, Tomaskova H, Janout V. Epidemiological of and risk factors for Alzheimer's disease. Biomed Pap Med FacUnivPalacky Olomouc Czech Repub 2012; 156 (2):108-114.

5. Plasman BL, Langa KM, Fisher GG, Heeringa SG, Weir DR, Ofstedal MB, Burke JR, Hurd MD, Potter GG, Rodgers WL, Steffens DC, Wills RJ, Wallace RB. Prevelance of dementia in the United States: The Aging, demographics, and memory study. Neuroepidemiology 2007; 29:125-132.

6. Kawas C, Grey S, Brookmeyer R, Fozard J, Zonderman A. Agespesific incidence rates of Alzheimer's diease: The Baltimore Longitunial study of aging. Neurology 2000; 54: 2072-207.

7. Kukull WA, Higdon R, Bowen JD, Mccormick WC, Teri L, Schellenberg GD, Van Belle G, Jolley L, Larson EB. Dementia and Alzheimer's diease incidence: A prospective cohort study. Arch Neurol2002; 59:1737-46.

8. Gürvit $\mathrm{H}$, Emre $\mathrm{M}$, Tinaz $\mathrm{S}$. The prevalence of dementia in an urban Turkish population. Am J Alzheimers Dis Other Demens 2008; 23(1): 67-76.

9. Chung SH. Aberrant phosphorylation in the pathogenesis of Alzheimer's disease. BMB Rep 2009; 42:467-74. 
10. Edelberg HK, Wei JY. The biology of alzheimer's disease. Mech Ageing Dev 1996; 91:95-114.

11. Özkay ÜD, Öztürk $Y$, Can ÖD. Yaşlanan dünyanın hastalığı: Alzheimer hastalığı. SDÜ Tıp Fakültesi Dergisi 2011; 18(1):35-42.

12. Reitz C, Brayne C, Mayeux R. Epidemiology of Alzheimer disease. Nature Reviews Neurology 2011; 7:137-152.

13. Karaman, Y. Alzheimer hastalığı ve diğer demanslar. 1. Baskı. Ankara: Lebib Yalkın Matbaası, 2002.

14. Yazıcı T, Şahin E. Alzheimer Hastalığı. Klin. GelişimDerg, 2010; 3:1-8

15. Rossor MN. The Dementias. Neurology in clinical practice, 3. Baskı, 2. Cilt, 2000; 1701-1718, U.S.A.

16. Ignatavacıus DD, Workman MI. Medical Surgical Nursing. 2.nd Edition 1995; 1153-1156.

17. Küçükgüçlü Ö. Alzheimer hastalığı ve hemşirelik bakımı. Demans Dergisi, 2003; 3:86-92.

18. Klatka LA, Schiffer RB, Powers JM, Kazee AM. Incorrect diagnosis of Alzheimer's disease: A clinicopathologic study. Arch Neurol 1996; 53(1):3542.

19. American Psychiatric Association. Diagnostic and statistical manual of mental disorders (5th ed.). Washington, DC, 2013.

20. Türkiye Beslenme Rehberi TÜBER 2015, T.C. Sağlık Bakanlığı Yayın No: 1031, Ankara 2016.

21. Patterson C, Feightner JW, Garcia A, Hsiung R, MacKnight C, Sadovnick AD. Diagnosis and treatment of dementia: 1. Risk assessment and primary prevention of Alzheimer disease. CMAJ, 2008; 178 (5): 546- 555

22. Bonda DJ, Wang X, Perry G, Nunomura A, Tabaton $M$, Zhu X. Oxidative stress in Alzheimer disease: A possibility for prevention. Neuropharmacology 2010; 59: 290-4.

23. Bolluk S, Tek A. Alzheimer'dan korunmada akdeniz diyeti. Akad Geriatr. Derg2014; 6: 55-61.

24. Seshadri S, Wolf PA. Homocysteine and the brain: Vascular risk factor or neurotoxin? Lancet Neurol 2003; 2:11.

25. Solfrizzi V, Panza F, Frisardi V, Seripa D, Logroscino G, Imbimbo BP. Diet and Alzheimer disease risk factors or prevention. Expert Rev Neurother 2011; 11: 677-708.

26. Baysal A. Beslenme. Ankara: HatipoğluYayınları, 2009; 184-187. 
27. Kontush K, Schekatolina S. Vitamin $E$ in neurodegenerative disorders: Alzheimer disease. Ann N Y Acad Sci 2004; 1031:249-62.

28. Engelhart MJ, Geerlings MI, Ruitenberg A, Swieten JC, Hofman A, Witteman JC, Breteler MB. Dietary intake of antioxidants and risk of Alzheimer disease. JAMA 2002; 287:3223-9.

29. Sano M, Ernesto C, Thomas RG. A controlled trial ofselegiline, alphatocopherol or both as treatment for Alzheimer disease: The alzheimer's disease cooperative study. N. Eng. J. Med 1997; 336:1216-1222.

30. Zandi PP, Anthony JC, Khatchaturian AS. Reduced risk of Alzeimer disease in users of antioxidants vitamin suplemantts. Arch Neurol 2004; 61;82-88.

31. Mcmahon J, GreenTJ, Skeaff CM, Knight RG, Mann JL, Williams SM. A controlled trial of homocystein lowering and cognitive performance. $\mathrm{N}$ Engl J Med,2006; 354(26):2764-72.

32. Durga J, Van Boxtel MP, Schouten EG. Effect of 3-year folic acid supplementation on cognitive function in older adults in the FACIT trial: A randomised, double blind, controlled trial. Lancet 2007; 369 (9557):208-21

33. Ono K, Yamada M. Vitamin A and Alzheimer's disease. GeriatrGerontollnt 2012; 12: 180-188.

34. Perrig WJ, Perrig J, Stehalin HB. The relation between antioxidants and memory performance in the old and very old. J Am GeriatrSoc,1997; 45(6):718-24.

35. Grimm M, Mett J, Hartmann T. The impact of vitamin $E$ and other fatsoluble vitamins on alzheimer'sdisease. Int J Mol Sci, 2016;17(1785):2-8.

36. Annweiler C, Faaantino B, Parot-Schincal E, Thiery S, Gautier $J$,Beauchet $O$. Alzheimer's disease -input of vitamin $D$ with mEmantineassay (AD-IDEA trial): Study protocol for a randomized controlled trial. Trials, 2011; 12:230.

37. Przybelski R, Agrawal S, Krueger D, Engelke JA, Walbrun F, Binkley $\mathrm{N}$. Rapid correction of low vitamin $\mathrm{D}$ status in nursing home residents. Osteoporos Int, 2008; 19(11):1621-1628.

38. Morris MC. The role of nutrition in alzheimer's disease: Epidemiological evidence. Eur J Neurol, 2009; 16: 1-7.

39. Morris MC, Evans DA, BienasJL. Consumption of fish and $n-3$ fattyacids and risk of incident Alzheimer disease. ArchNeurol, 2003; 60:940-6.

40. Ortega RM, Requejo AM, Andres P. Dietaryintakeandcognitivefunction in a group of elderlypeople. Am J ClinNutr, 1997; 66:803-9. 
41. Vural H, Demirin H, Kara $\mathrm{Y}$, Eren I, Demirbaş N. Alterations of plasmamagnesium, copper, zinc, ironandseleniumconcentrationsandsomerelatederythrocyteantioxidante nzymeactivities in patientswithAlzheimer'sdisease. J Trace Elem Med Biol, 2010; 24:169-173.

42. Basun $H$, Forssell LG, Wetterbelg $L$, Winblad $W$. Metalsandtraceelements in plasmaandcerebrospinalfluid in normal agingandAlzheimer'sdisease. J Neural Transm Park Dis Dement Sect, 1991; 3(4):231-258.

43. Sevim S, Ünal Ö, Tamer L, Doğu O, Özge A. Can serum levels of copperandzincdistinguishAlzheimer'spatientsfrom normal subjects?J Neurol Sci, 2007; 24(3):197-205. 
